\title{
STRATEGI PENGEMBANGAN TEKNOLOGI PENGOLAHAN SAGU PADA UMKM DI PROVINSI RIAU
}

\author{
Gevisioner $^{1^{*}}$, Candra Sari Mutiara ${ }^{1)}$ \\ ${ }^{1}$ Badan Perencanaan Pembangunan Daerah Penelitian dan Pengembangan Provinsi Riau \\ ${ }^{*}$ Corresponding author: irgevisioner@gmail.com \\ To cite this article: \\ Gevisioner, G., \& Mutiara, C. (2020). Strategi Pengembangan Teknologi Pengolahan Sagu pada UMKM di \\ Provinsi Riau. JIA (Jurnal IImiah Agribisnis) : Jurnal Agribisnis dan Ilmu Sosial Ekonomi Pertanian, 5(6), 229 \\ 236. doi:http://dx.doi.org/10.37149/jia.v5i6.14228
}

Received: September 22, 2020; Accepted: December 27, 2020; Published: December 31, 2020

\section{ABSTRACT}

The community and industry have been developing sago products. However, the downstream industrial development of sago products carried out by the community is still very limited, both in terms of type and quality. The aim of this study was to formulate strategies and policies for the development of technology for downstream sago products, especially sago noodles. The study was conducted in the Meranti Islands District in 2019, with a sample of 40 sago noodle micro, small and medium enterprises (MSMEs). Data collection was carried out by means of surveys and focus group discussions (FGD). Data analysis using SWOT analysis. The results of the research found that the majority of sago processing technology was still traditional and semi-modern and $87.5 \%$ of the sago noodle product quality was not good. Efforts to organize the production space according to product hygienic sanitation standards and improve sago noodle product packaging technology are the right strategies to improve the quality of sago noodles. Therefore the policy of developing sago noodle downstream product technology is implemented by Building supporting facilities for the smooth running of the sago noodle business, such as providing clean and proper water facilities for processing sago noodles, Providing socialization, and improving the quality of human resources regarding quality and sago noodle packaging.

Keywords: innovation cluster; MSMEs; Riau; sago noodles; technology.

\section{PENDAHULUAN}

Salah satu sumber pangan lokal yang mempunyai potensi sangat besar di Indonesia baik sebagai bahan cadangan pangan dan bahan baku industri pangan adalah tanaman sagu (Metroxylon sp) (Kementerian Pertanian, 2014). Indonesia memiliki 51,3 persen dari 2,2 juta ha areal lahan sagu di dunia. Papua, Sulawesi dan Riau, merupakan daerah potensial penghasil sagu di Indonesia Produksi sagu nasional saat baru mencapai sekitar 8 persen dari potensi sagu nasional, yakni 800.000 ton per tahun (Santoso, A, 2017).

Luas areal tanaman sagu di Provinsi Riau hingga tahun 2016 mencapai $83.671 \mathrm{Ha}$. Tanaman sagu tersebar di kabupaten Kepulauan Meranti, Indragiri Hilir, Bengkalis, Rokan Hilir, Pelalawan, Siak. Produksi sagu dalam bentuk tepung pada tahun 2017 mencapai 366.032 ton, dengan rata-rata peningkatan 5,18 persen setiap tahunnya (BPS Provinsi Riau, 2018). Luas tanaman sagu terbesar terdapat di kabupaten Kepulauan Meranti yang mencapai $50.193 \mathrm{Ha}$, yang terdiri dari tanaman sagu rakyat seluas $38.399 \mathrm{Ha}$ dan tanaman sagu perusahaan 11.794 Ha (BPS Kabupaten Kepulauan Meranti, 2018).

Di Kabupaten Kepulauan Meranti pemanfaatan sagu juga telah dikenal sangat lama. Sehingga komoditas sagu telah menjadi prioritas pembangunan dengan menempatkan sebagai komoditi unggulan daerah. Hal ini, tentu tidak terlepas dari bagaimana upaya pemerintah untuk tetap mempertahankan komoditi perkebunan sebagai tanaman primadona dan tetap dipertahankan sebagai jatidiri daerah. Oleh sebab itu kehidupan sosial masyarakat di Kabupaten Kepulauan Meranti sangat dipengaruhi oleh perkembangan komoditi tersebut baik di on farm maupun di off farmnya (Balitbang Riau, 2018) 
Produk sagu selama ini telah dilakukan pengembangannya oleh masyarakat dan industri melalui usaha mikro kecil dan menengah (UMKM). Namun perkembangan industri hilir dari produk sagu yang dilakukan oleh UMKM masih sangat terbatas, baik dari segi jenis maupun mutunya (Helviani, 2018). Terbatasnya kapasitas usaha dan diri pada pengolah sagu menyebabkan produk yang dihasilkan belum berkembang sesuai kebutuhan konsumen di pasaran (Tahitu, ME, dkk, 2016)

Jumlah UMKM di kabupaten Kepulauan Meranti pada tahun 2016 sebanyak 2385 UMKM yang terdaftar, terdapat sebanyak 137 UKM yang bergerak di bidang usaha sagu, mulai usaha mie sagu, hingga berbagai kue mueh lainnya (Dinas Perindustrian Perdagangan dan UKM Kabupaten Kepulauan Meranti, 2017). Jenis produk yang dihasilkan oleh UMKM sagu sebanyak 12 produk. Dengan kata lain rata-rata usaha pengolahan sagu tradisional di Kabupaten Kepulauan Meranti menghasilkan 1-2 jenis produk. Produk yang terbanyak dihasilkan adalah mie sagu (48,72 \%) dan sagu rendang (15,38 \%) (Saghita, EP, dkk, 2018).

Mie sagu merupakan ciri khas bahan makanan di Kabupaten Kepulauan Meranti dan penjualan hasil industri mie sagu sudah sampai ke kabupaten tetangga seperti Siak, Bengkalis dan Karimun. Perusahaan mie Sagu yang ada saat ini belum sanggup untuk memenuhi permintaan dari Kotamadya Batam karena skala usaha yang masih kecil sehingga secara ekonomi belum menguntungkan jika dilakukan pengiriman mie sagu dengan jumlah produksi saat ini sehingga merupakan suatu peluang investasi (Maharani, E dan Kusumawaty, Y, 2014)

Mie sagu yang dihasilkan dari pengolahan tepung sagu bila dibandingkan dengan mie yang berasal dari tepung terigu atau yang lainnya tentu mempunyai kekurangan antara lain : a) Mie sagu terlalu kenyal dibandingkan dengan mie yang lain sehingga mempengaruhi penyerapan rasa oleh mie pada kuliner, b) Mie sagu yang diproduksi adalah dalam bentuk basah sehingga mempengaruhi biaya pengiriman, c) Kemasan mie sagu masih bersifat untuk memungkinkan kontak dengan cuaca dari luar, d) Belum ada pengukuran standar baku (SNI) terhadap dari mie sagu yang dihasilkan. Sedangkan kelebihan dari mie sagu adalah : a) Memiliki daya simpan yang lama bila dibandingkan dengan mie yang lain, b) Harga jual dapat lebih murah dari mie yang lain karena harga bahan baku yang rendah, c) Tidak memiliki bau yang khas sehingga tidak mempengaruhi aroma masakan (Haryanto Bambang, dkk, 2015).

Kemampuan industri kecil/UMKM dalam menyesuaiakan kondisi produk dengan selera pasar atau konsumen (Drucker, Peter, F, 2002), komponen teknologi yang sangat terbatas baik kuantitas dan kualitas pada UMKM (Sedyatuti Kristina, 2018), kurang memperhatikan mutu dan keamanan produk (Fatimah Tjutju, 2011) merupakan beberberapa tantangan dan permasalahan yang dihadapi industri kecil/UMKM dalam pengembangan produknya. Oleh sebab itu peningkatan kemampuan usaha UMKM harus memperhatikan kondisi UMKM yang sebenarnya (Tahitu, ME, dkk, 2016) Dalam rangka mengatasi permasalahan dan tantangan yang ada dalam pengembangan UMKM mie sagu, perlu diirumuskan strategi yang tepat yang dihadapi UMKM mie sagu di kabupaten Kepulauan Meranti. Penelitian ini mempunyai tujuan merumuskan strategi pengembangan teknologi pengolahan mie sagu.

\section{MATERI DAN METODE}

Penelitian dilaksanakan di Kecamatan Tebing Tinggi dan Kecamatan Tebing Tinggi Barat. Kabupaten Kepulauan Meranti. Lokasi penelitian ditentukan secara purposive, yakni sentra pengolahan sagu. Pengumpulan data berlangsung selama enam bulan, yaitu pada bulan April hingga Oktober 2019. Populasi penelitian ini adalah 67 usaha mikro, kecil dan menengah (UMKM) mie sagu, sedangkan jumlah sampel sebanyak 40 UMKM yang ditentukan dengan rumus Slovin. Penyebaran sampel yakni 22 di Kecamatan Tebing Tinggi dan 18 di Kecamatan Tebing Barat. Penentuan sampel dilakukan secara acak sederhana dengan menggunakan tabel acak (Nazir, M, 2003). Jenis data yang di kumpulkan meliputi data primer dan sekunder. Data primer berupa karakteristik UMKM yang meliputi usia, pendidikan terakhir pemilik UMKM, kemampuan modal, keuntungan, kualitas produk dan permasalahan pengembangan produk. Teknik pengumpulan data primer yang digunakan dalam penelitian adalah wawancara dengan kuesioner dan diskusi kelompok terfokus (FGD). Data sekunder diperoleh dari laporan instansi terkait yang menunjang tujuan penelitian. Analisis SWOT dilakukan untuk pemetaan prioritas strategi pengembangan produk mie sagu di Kabupaten Kepulauan Meranti. Dalam proses penyusunan Internal Factor Analysis Summary (IFAS) dan Eksternal Factor Analysis Summary (EFAS) melalui tahapan sebagai berikut : (a) Faktorfaktor yang menjadi kekuatan dan kelemahan serta peluang dan ancaman industri Mie sagu diidentifikasi, b). Faktor-faktor yang telah diidentifikasi diberi bobot dengan skala 0,0 (tidak penting) sampai dengan 1,0 (sangat penting), jumlahnya bobot tidak melebih skor total 1,00; (c) Masingmasing faktor diberi rating, dengan memberikan skala mulai dari 1 (dibawah rata-rata hingga 4 
(sangat baik), (d) Kemudian melakukan perkalian antara bobot dan rating untuk memperoleh nilai skor (David, F.R, 2002). Pendapat pakar (UMKM dan stakeholder) merupakan sumber dalam penentuan nilai bobot dan rating. Strategi dengan bobot nilai tertinggi merupakan strategi prioritas untuk dilaksanakan. Sedangkan data karakteristik UMKM dianalisis secara deskriptif.

\section{HASIL DAN PEMBAHASAN}

\section{Karakteristik UMKM Mie Sagu}

Setiap usaha memiliki karakteristik sosial dan ekonomi yang berbeda. Karakteristik ini mempengaruhi perilaku dalam pengembangan usaha, oleh sebab itu pemahaman perilaku sosial UMKM mie sagu sangat diperlukan dalam pengembangannya.

\section{a. Karakteristik Responden}

Pemilik UMKM mie sagu di Kabupaten Kepulauan Meranti didominasi 72,50 persen wanita, sedangkan pria hanya sebesar $(27,50 \%)$ (Tabel 1$)$, dengan penyebaran umur terbanyak pada usia 46 hingga 60 tahun $(47,50 \%)$ serta pendidikan formal teringgi yang pernah diikuti adalah sekolah dasar dan tingkat SLTP sebanyak 57,50 persen dan tingkat SLTA sebesar 42,50 persen (Tabel 1). Kondisi ini memperlihatkan usaha mie sagu dapat diandalkan sebagai sumber penghasilan rumah tangga, karena banyak diminati kaum perempuan yang berusia produktif.

Tabel. 1. Sebaran UMKM menurut jenis kelamin, umur, pendidikan formal tertinggi pemilik di Kabupaten Kepulauan Meranti Provinsi Riau Tahun 2019.

\begin{tabular}{cccc}
\hline No & \multicolumn{1}{c}{ Karakteristik } & $\mathrm{n}$ & $\%$ \\
\hline 1 & Jenis Kelamin Pemilik & 11 & \\
& - Pria & 11 & 27,50 \\
& - Wanita & 29 & 72,50 \\
& Umur Pemilik (Tahun) & & \\
& $-25-45$ & 15 & 37,50 \\
& $-46-60$ & 19 & 47,50 \\
& $->60$ & 6 & 15,00 \\
3 & Pendidikan Tertinggi Pemilik & & \\
& - Sekolah Dasar & 8 & 20,00 \\
& - SLTP & 15 & 37,50 \\
& - SLTA & 17 & 42,50 \\
\hline
\end{tabular}

Sumber : Hasil Survei (2019).

Pengembangan teknologi ke depan sangat diperlukan peningkatan pengetahuan dan keterampilan pemilik usaha mie sagu, karena keterbatasan pendidikan formal yang dialami pemilik usaha. Hasil penelitian juga menunjukkan bahwa bahwa pendidikan non formal yang pernah diikuti oleh UMKM sangat terbatas. Pemilik UMKM di kabupaten Kepulauan Meranti menyatakan bahwa dalam dua tahun terakhir pendidikan non formal masih dirasakan sangat kurang. Sedangkan untuk mempersiapkan perilaku pengusaha dalam menghadapi tantangan diperlukan pelatihan (Fatimah Tjutju, 2011). Kemampuan mengembangkan usaha menjadi statis dan menjurus rutinitas, apabila tidak diiringi dengan kemampuan meningkatkan pengetahuan dan keterampilan (Sedyatuti Kristina, 2018).

\section{b. Kapasitas UMKM Mie Sagu}

UMKM mie sagu memiliki tenaga kerja $4-6$ orang dengan persentase terbesar yakni 60 persen, namun terdapat 27,50 persen UMKM yang memiliki tenaga kerja 1-3 orang (Tabel 2). Tenaga kerja sendiri dan dalam keluarga merupakan sumber tenaga kerja pada UMKM berbahan sagu di kabupaten Kepulauan Meranti, tenaga kerja dari luar keluarga digunakan bila tenaga kerja kurang. Selama ini kuantitas tenaga kerja cukup memadai, namun dari kualitas masih rendah. Masih rendahnya kualitas ketrampilan pekerja, menyebabkan pemilik usaha ikut dalam proses produksi. Sehingga untuk menjaga kualitas mie sagu, sering proses produksi berhenti, bila pemilik tidak berada dilokasi usaha.

Terdapat 40 persen UMKM mie sagu memiliki modal usaha lebih dari 10 juta dan 60 persen memiliki modal usaha kurang dari Rp 10 juta. UMKM memiliki keuntungan lebih dari Rp. 5 juta setiap bulan sebanyak 45 persen (Tabel 2), sehingga usaha mie sagu masih menjadi usaha paling banyak diminati masyarakat di Kabupaten Kepulauan Meranti karena selain dari aspek sosial yang mendukung juga dari segi finansial lebih menguntungkan. Ini sejalan dari hasil analisis finansial 
industri pengolahan mie sagu menunjukkan layak diusahakan dengan memakai kriteria NPV $>0$, IRR $(18,18 \%)>$ dari suku bunga $12 \%$, Net $\mathrm{B} / \mathrm{C}(1,72)>1$ dan payback periode selama 2,24 tahun (Bank Indonesia, 2014). Kondisi ini juga didukung hasil temuan Hariyanto, dkk (2015), menghitung nilai tambah mie sagu yang dihitung dalam nilai rupiah, ditemukan bahwa harga mie sagu sangat kompetitif dibanding dengan mie telor dipasaran. Selain itu diperoleh nilai tambah 5-6 kali dari bahan baku sagu.

Tabel. 2. Sebaran UMKM mie sagu menurut kapasitas usaha di Kabupaten Kepulauan Meranti Provinsi Riau Tahun 2019.

\begin{tabular}{|c|c|c|c|}
\hline \multirow{5}{*}{$\begin{array}{c}\text { No } \\
1\end{array}$} & Karakteristik & $\mathrm{n}$ & $\%$ \\
\hline & $\begin{array}{l}\text { Jumlah Tenaga Kerja (orang) } \\
\text { (orang) }\end{array}$ & & \\
\hline & $-1-3$ & 11 & 27,50 \\
\hline & $-4-6$ & 24 & 60,00 \\
\hline & $->6$ & 5 & 12,50 \\
\hline \multirow[t]{4}{*}{2} & Modal Usaha (Rp/bulan) & & \\
\hline & $-<5 j u t a$ & 15 & 37,50 \\
\hline & $-5-10$ juta & 9 & 22,50 \\
\hline & -10 juta & 16 & 40,00 \\
\hline \multirow[t]{4}{*}{3} & Keuntungan Usaha (Rp/bulan) & & \\
\hline & $-<1$ juta & 10 & 25,00 \\
\hline & $-1-5$ juta & 12 & 30,00 \\
\hline & $->5$ juta & 18 & 45,00 \\
\hline \multirow[t]{4}{*}{4} & Kualitas Produk & & \\
\hline & - Belum baik & 11 & 27,50 \\
\hline & - Cukup baik & 24 & 60,00 \\
\hline & - Baik & 5 & 12,50 \\
\hline \multirow[t]{4}{*}{5} & Pemasaran & & \\
\hline & - Langsung ke konsumen & 22 & 55,00 \\
\hline & - Titip di warung/pasar & 11 & 27,50 \\
\hline & - Keluar daerah & 7 & 17,50 \\
\hline
\end{tabular}

Sumber : Hasil survei (2019)

Hasil penelitian juga ditemukan bahwa UMKM mie sagu sudah mulai melakukan aktivitas menabung, tetapi keuangan usaha belum dapat dipisahkan dengan keuangan rumah tangga. Pengembangan usaha pengolahan sagu masih sulit dilakukan, karena keterbatasan akses kesumbersumber modal. Modal milik sendiri masih menjadi andalan bagi pengembangan usaha pengolahan sagu (Gevisioner, dkk, 2018). Struktur permodalan dan keterbatasan untuk memperoleh sumber modal yang memadai, merupakan permasalahan dasar yang dihadapi UMKM (Setyanto, AR, dkk, 2015).

Proses pembuatan mie sagu pada UMKM di kabupaten Kepulauan Meranti sebagai berikut : a) Proses pengadukan sagu : sagu yang telah disiapkan kemudian diaduk hingga rata didalam bak yang telah disiapkan, b) Proses pemanasan sagu : setelah sagu diaduk kemudian sagu dipanaskan sambil diaduk didalam kuali hingga rata sehingga adonan sagu padat supaya dapat digiling, c) Proses penggilingan (press) : sagu yang telah dipanaskan dan sudah berupa adonan padat kemudian digiling dengan mesin press sehingga mie sagu berbentuk lempengan, d) Proses penggantungan : mie sagu yang sudah digiling berbentuk lempengan kemudian di gantung dengan waktu 1 hari, e) Proses pencetakan : mie sagu yang sudah di gantung selama 1 hari kemudian dicetak dengan mesin pencetak sehingga terbentuk mie sagu, f) Proses pengemasan : mie sagu yang sudah di cetak kemudian dikemas dan sudah siap dipasarkan.

Komponen teknologi UMKM mie sagu di kabupaten Kepulauan Meranti masih rendah. Rendahnya komponen teknologi dapat dilihat dari belum ada penambahan variasi produk, volume produksi tidak meningkat, mutu dan keamanan produk kurang diperhatikan. Hal ini disebabkan sebagian besar peralatan kurang layak pakai dan proses pengolahan masih berdasarkan kebiasaan yang dilakukan selama ini. Kondisi ini berdampak kepada hasil produk yang kurang terjamin higenitasnya serta penggunaan waktu yang kurang efisien (Harahap, AR dan A. Hendry, 2016). Untuk menambah nilai jual produk UMKM, pengembangan sumberdaya manusia dan teknologi, inovasi dan jasa serta perluasan pemasaran harus dilakukan UMKM agar mampu menghadapi tantangan global yang ada (Hapsari Aldina dan Rilus AK, 2018). 
Sebagian besar UMKM mie sagu, belum memprioritaskan unsur higienitas. Kondisi ini dapat dilihat dari bentuk pengemasan produk yang dilakukan menggunakan plastik yang direkatkan seadanya dengan bantuan api kecil, ruangan tempat proses pengolahan sagu umumnya menyatu dengan dapur rumah, belum memiliki ijin usaha dan mengujikan produk ke BPOM karena keterbatasan biaya (Timisela, NR, dkk, 2014). Sifat usaha yang merupakan usaha keluarga yang turun menurun, dan telah puas dengan kondisi yang ada juga faktor penyebab rendahnya pemahaman pengelola sagu terhadap legalitas produk ( Santoso, A, 2017). Hal ini didukung dengan hasil penelitian bahwa ternyata 60 persen UMKM mie sagu menyatakan hasil produk mie sagu cukup baik, dan 12,50 persen sudah baik (Tabel 2). Terbatasnya modal, ketrampilan dan kepuasan terhadap produk yang ada saat ini, merupakan alasan pengolah sagu belum merasa perlu meningkatkan kualitas produk (Tahitu, ME, dkk. 2016). Belum adanya sosialisasi tentang pentingnya memenuhi suatu standar dan izin untuk meningkatkan daya jual dan daya saing produk tepung sagu , juga merupakan faktor masih rendahnya pemahaman UMKM untuk meningkatkan kualitas produknya (Bank Indonesia, 2014)..

Terdapat 87,5 persen UMKM mie sagu memasarkan produknya di dalam kabupaten Kepulauan Meranti, hanya 17,5 persen UMKM mie sagu yang menjual produknya keluar kabupaten Kepulauan Meranti. UMKM merasakan belum ada kesulitan dalam memasarkan produk, hal ini disebabkan tidak ada persaingan, harga jual sudah memadai karena masing-masing UMKM memiliki pelanggan. Meskipun beberapa UMKM masih mengharapkan peningkatan harga jual. Dukungan dari pemerintah daerah dan swasta yang sangat diharapkan UMKM untuk dalam pengembangan produknya (Setyanto, AR, dkk, 2015). Pengembangan pasar produk sagu masih terbuka untuk pasar lokal ataupun pasar International. Namun rendahnya produktivitas, mutu dan produksi menjadi kendala dalaam memenuhi permintaan pasar (Bank Indonesia, 2014).

UMKM masih mengharapkan dukungan dari pemerintah dan swasta, karena dukungan dalam bentuk fisik maupun non fisik selama ini masih sangat terbatas. Sebagian besar UMKM ( > $90 \%$ ) menyatakan belum memperoleh dukungan dalam bentuk fisik dari pemerintah/pemerintah daerah, 60 persen telah memperoleh dukungan dalam bentuk non fisik (Gambar 1). Hanya 2,5 persen UMKM mie sagu yang menyatakan memperoleh dukungan fisik dari pihak swasta, dan 7,50 persen dukungan non fisik. Dukungan fisik selama ini berupa bantuan peralatan, sedangkan dukungan non fisik meliputi pelatihan peningkatan mutu dan pemasaran produk mie sagu.

Wawancara mendalam dengan pemilik UMKM mie sagu diperoleh bahwa informasi tentang peluang pengembangan usaha seperti perluasan pasar, akses modal, manajemen usaha, teknologi inovatif produk dari sagu, pengemasan dan prosedur memperoleh izin usaha dan pengujian mutu produk, merupakan informasi yang paling banyak dibutuhkan UMKM mie sagu.

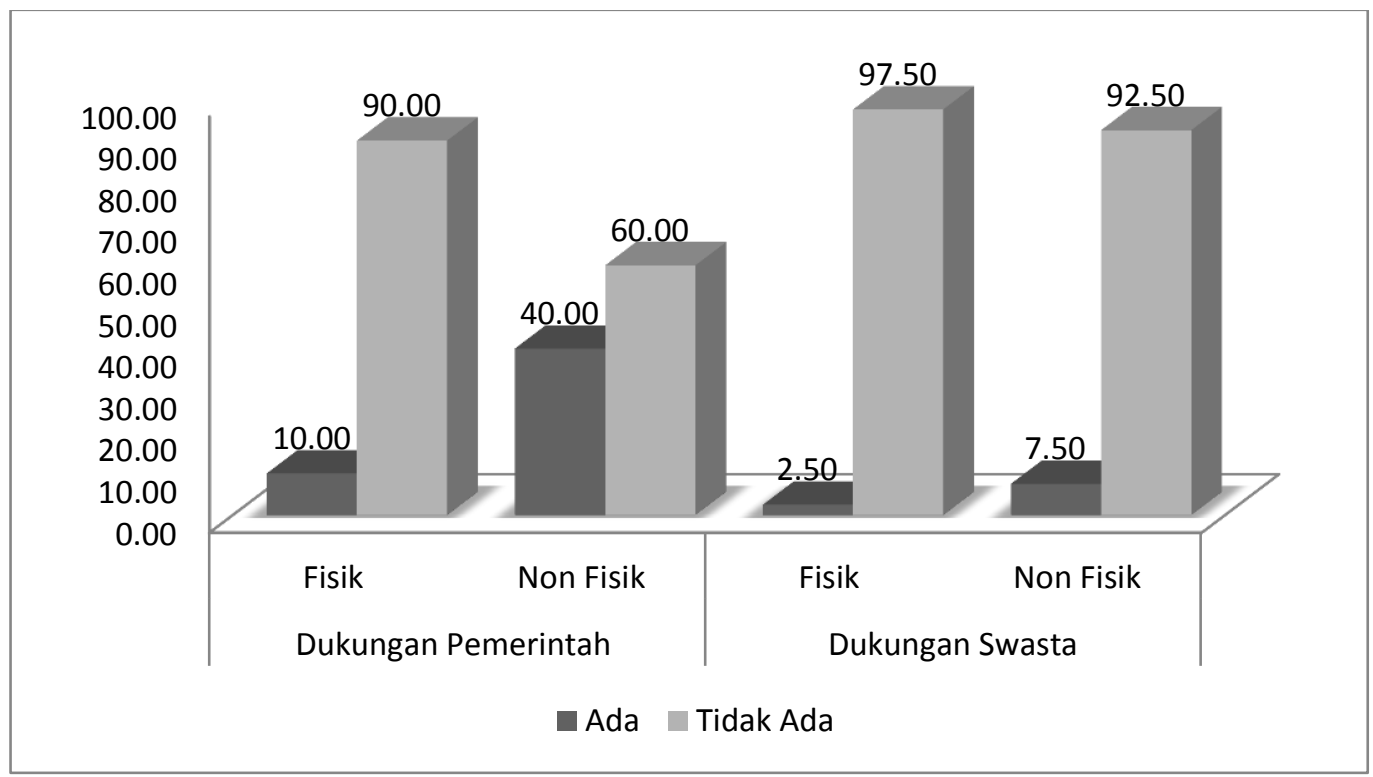

Gambar 1. Dukungan pemerintah dan swasta terhadap UMKM di Kabupaten Kepulauan Meranti

\section{Strategi Pengembangan Teknologi}

Hasil identifikasi kekuatan, kelemahan,tantangan dan peluang terhadap pengembangan usaha mie sagu diperoleh bahwa faktor internal yang dilihat dari aspek kekuatan yaitu : a) Bahan 
baku yang melimpah dan kontinyu, b) Tingkat persaingan produk rendah, c) Bargaining position/penguasaan pasar tinggi, d) Produk pengganti pangan yang dibutuhkan banyak orang (Santoso, A, 2017),e) Jaringan pemasaran cukup baik dan f) Peluang pasar luas (Haryanto Bambang, dkk, 2015). Faktor internal yang dilihat dari aspek kelemahan yaitu sebagai berikut: a) Keterbatasan akses transportasi, b) Infrastruktur jalan masih kurang ketersediaan air bersih terbatas , c) Belum ada kontrol hasil komoditi dan produk olahan sagu belum memiliki standar tertentu (Bank Indonesia, 2014),d) Kemasan untuk pemasaran yang belum menarik/masih tradisional mempengaruhi daya tahan produk dan mutu dan e) Daerah pemasaran masih terbatas (Maharani, E dan Kusumawaty, Y, 2014).

Faktor eksternal yang dilihat dari aspek peluang yaitu sebagai berikut: a) Mie sagu sebagai pangan alternative pengganti mie terigu, b) Dapat dipadukan dengan bahan pangan lainnya, c) Tidak banyak terdapat pabrik mie sagu didaerah lain, d) Adanya permintaan dari daerah lain yang belum terpenuhi, e) Didukung oleh pemerintah sebagai kawasan klaster dan f) Daya tahan produk yang lama (Haryanto Bambang, dkk. 2015). Faktor eksternal yang dilihat dari aspek ancaman yaitu sebagai berikut: a) Belum sanggup memenuhi MOU yang diinginkan oleh pembeli (Bank Indonesia, 2014), b) Mutu/kualitas komoditi dan produk yang belum konsisten sehingga pasar menjadi tidak stabil (Helviani, 2018), c) Harga transportasi yang tinggi menyebabkan daya saing produk rendah.

Hasil analisa lebih lanjut terhadap terhadap Internal Factor Analysis Summary (IFAS) diperoleh nilai skor untuk faktor kekuatan 1,70 dan nilai skor untuk faktor kelemahan 1,65. Sedangkan analisa terhadap Eksternal Factor Analysis Summary (EFAS) diperoleh hasil nilai skor untuk faktor peluang adalah 1,85 dan faktor ancaman adalah 1,35. Hasil pengurangan nilai skor kekuatan dengan ancaman diperoleh selisih nilai (+) 0,05, artinya nilai faktor kekuatan melebihi nilai faktor kelemahan. Nilai faktor peluang di atas nilai skor ancaman dengan selisih nilai (+) 0,50 (Gambar 2).

Berdasarkan diagram kartesius SWOT yang disajikan pada Gambar 2, menunjukkan pengembangan teknologi mie sagu berada pada kuadran I artinya bahwa strategi pengembangan teknologi mie sagu adalah strategi SO, yaitu strategi meningkatkan kekuatan dan menangkap semua peluang yang ada.

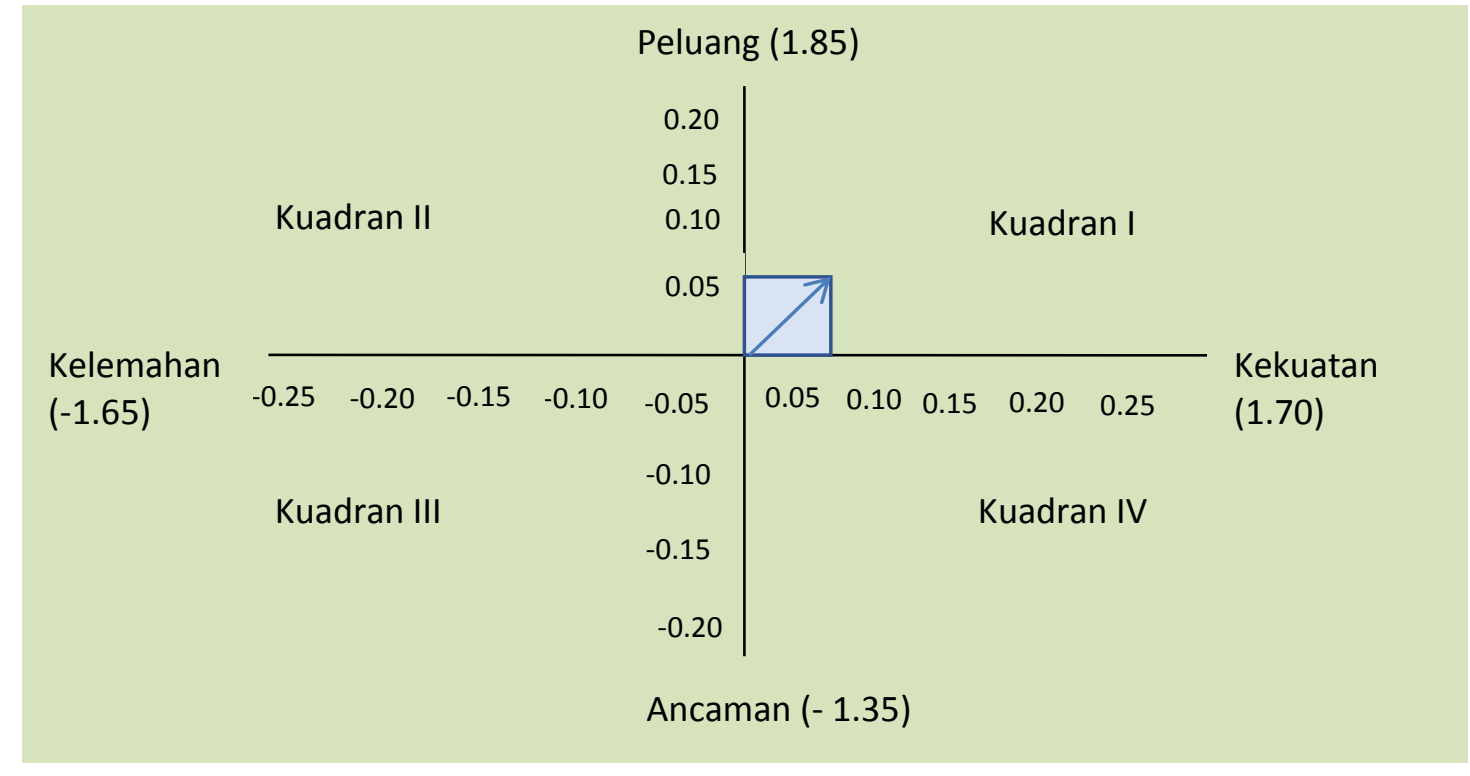

Gambar 2. Diagram Kartesius SWOT mie sagu

Rumusan strategi yang dapat mendukung keberlanjutan dan ketahanan usaha di bidang pengolahan komoditi hilir sagu khususnya produk mie sagu di Kabupaten Kepulauan Meranti, yang harus dipersiapkan oleh pihak-pihak yang berkompeten antara lain: a). Meningkatkan kemitraan dan hubungan baik dengan pemasok tepung sagu sebagai bahan baku utama pembuatan mie sagu (Harahap, AR dan A. Hendry, 2016), c) Membuat variasi kemasan (jenis dan ukuran kemasan) mie sagu sesuai dengan permintaan dan pasar, dibuat kemasan berbagai ukuran berat, menarik, ditampilkan tulisan tentang kualitas barang, kadaluarsa dan cara penyimpanan (Balitbang Riau, 2018), d) Menyebarluaskan informasi, promosi atas keragaman pangan dari mie sagu dan manfaat mengkonsumsi mie sagu dari aspek kesehatan manusia dan pemenuhan gizi masyarakat, e). Memperluas pasar dan jalur distribusi mie sagu pada daerah-daerah yang membutuhkan keragaman pangan, f) Memperbaharui mesin-mesin produksi secara berkala untuk mendapatkan hasil produksi 
dan peningkatan produksi mie sagu yang baik, melalui penguatan permodalan (Bank Indonesia, 2014), g) Meningkatkan pelayanan kepada konsumen mie sagu dan h) Menjaga mutu produk mie sagu secara konsisten kepada konsumen dan pihak user lainnya (Helviani, 2018).

\section{KESIMPULAN DAN SARAN}

Pengembangan teknologi pengolahan mie sagu di Kabupaten Kepulauan Meranti Provinsi Riau adalah meningkatkan kekuatan dan menangkap semua peluang yang ada. Terdapat 5 (lima) prioritas strategi yang dihasilkan yaitu : a). Meningkatkan kemitraan dan hubungan baik dengan pemasok tepung sagu sebagai bahan baku utama pembuatan mie sagu, b) Memperbaharui mesinmesin produksi secara berkala untuk mendapatkan hasil produksi dan peningkatan produksi mie sagu yang baik, melalui penguatan permodalan, c) Membuat variasi kemasan (jenis dan ukuran kemasan) mie sagu sesuai dengan permintaan dan pasar, dibuat kemasan berbagai ukuran berat, menarik, ditampilkan tulisan tentang kualitas barang, kadaluarsa dan cara penyimpanan, d) Menyebarluaskan informasi, promosi atas keragaman pangan dari mie sagu dan manfaat mengkonsumsi mie sagu dari aspek kesehatan manusia dan pemenuhan gizi masyarakat, e). Memperluas pasar dan jalur distribusi mie sagu. Strategi pengembangan teknologi pengolahan mie sagu di kabupaten Kepulauan Meranti harus didasarkan pada pengembangan berbasis kluster inovasi melalui sinergitas empat stakeholders utama, yaitu pemerintah, perguruan tinggi, dunia usaha, dan masyarakat. Klaster inovasi sagu menjadi alternatif karena memungkinkan sinergitas terjadi secara lebih baik sehingga peningkatan daya saing mie sagu dapat terwujud dengan cepat.

\section{UCAPAN TERIMA KASIH}

Pada kesempatan ini diucapkan terimakasih kepada Kepala Badan Penelitian dan Pengembangan Provinsi Riau dan Kepala Badan Perencanaan Pembangunan Daerah Kabupaten Kepulauan Meranti serta semua pihak, yang telah memberikan dukungan terhadap pelaksanaan penelitian ini.

\section{REFERENSI}

Balitbang Riau. (2018). Master Plan Model Pengembangan Klaster Inovasi Produk Unggulan Daerah Sagu Provinsi Riau. Pekanbaru: Badan Penelitian dan Pengembangan Provinsi Riau.

Bank Indonesia. (2014). Pola Pembiayaan Usaha Kecil Usaha Pengolahan Tepung Sagu. Batam: Bank Indonesia Kantor Perwakilan Bank Indonesia Provinsi Kepulauan Riau.

BPS Kabupaten Kepulauan Meranti. (2018). Kabupaten Kepulauan Meranti Dalam Angka 2017. Selat Panjang: Badan Pusat Statistik Kabupaten Kepulauan Meranti.

BPS Provinsi Riau. (2018). Provinsi Riau Dalam Angka Tahun 2017. Pekanbaru: Badan Pusat Statistik Provinsi Riau.

David, F.R. (2002). Manajemen Strategis Konsep. Jakarta: PT. Prenhallindo.

Dinas Perindustrian Perdagangan dan UKM Kabupaten Kepulauan Meranti. (2017). Profil Perindustrian Perdagagnan dan UKM. Selat Panjang: Dinas Perindustrian Perdagangan dan Usaha Kecil Menengah Kabupaten Kepulauan Meranti.

Drucker, Peter, F. (2002). The Dicipline of Innovation. Harvard: Harvard Business School Publishing Corporation.

Fatimah Tjutju. (2011). Strategi Pemberdayaan Usaha Mikro, Kecil dan Menengah (UMKM) dalam Menghadapi Globalisasi. Econo Sains, IX(1), 49-61.DOI: https://doi.org/10.21009/econosains.0091.06.

Gevisioner, dkk. (2018). Penguatan Kelembagaan Pengembangan Sagu di Kabupaten Kepulauan Meranti Provinsi Riau. Kebijakan Pembangunan dan Inovasi (IPTEKIN), 3;2, 11-19.

Hapsari Aldina dan Rilus AK. (2018). Hubungan Partisipasi dalam Program Pemberdayaan UMKM dengan Tingkat Kesejahteraan Peserta. Sains Komunikasi dan Pengembangan Masyarakat, 2(1), 1-12. DOl:https://doi.org/10.29244/jskpm.2.1.1-12.

Harahap, AR dan A. Hendry. (2016). Analisis Pemberdayaan Usaha Kecil Menengah Penghasil Produk Berbahan Baku Sagu di Desa Banglas Kecamatan Tebing Tinggi Kabupaten Kepulauan Meranti Provinsi Riau. Valuta, 2;2, 140-155.

Haryanto Bambang, dkk. (2015). Potensi dan Pemanfaatan Pati Sagu dalam Mendukung Ketahanan Pangan di Kabupaten Sorong Selatan Papua Barat. Pangan, 24;2, 97-106.

Helviani. (2018). Preferensi Konsumen Sagu di Kota Kendari. Sosio Agribisnis, 3(1), 16-29. DOI Crossref: dx.doi.org/10.33772/jsa. 
Kementerian Pertanian. (2014). Strategi Induk Pembangunan Pertanian 2015-2045, PertanianBioindustri Berkelanjutan Solusi Pembangunan Indonesia Masa Depan. Jakarta: Kementerian Pertanian RI.

Maharani, E dan Kusumawaty, Y. (2014). Strategi Pemasaran dan Persepsi Konsumen Sagu di Kelurahan Selat Panjang Selatan Kecamatan Tebing Tinggi Kabupaten Kepulauan Meranti. SEPA, 10;2, 305-314.

Nazir, M. (2003). Metode Penelitian. Jakarta: Ghalia Indonesia.

Saghita, EP, dkk. (2018). Penguatan Kapasitas UMKM di Kabupaten Kepulauan Meranti. Kebijakan Pembangunan dan Inovasi (IPTEKIN), 3;2, 89-99.

Santoso, A. (2017). Potensi dan Kendala Pengembangan Sagu sebagai Bahan Pakan, Pangan dan Kelestarian Lingkungan di Indonesia. JRL, 10(2), 51-57.

Sedyatuti Kristina. (2018). Analisis Pemberdayaan UMKM dan Peningkatan Daya Saing Dalam Kancah Pasar Global. Inovasi Bisnis dan Manajemen Indonesia, 2(1), 117-127.DOI: https://doi.org/10.31842/jurnal-inobis.v2i1.65.

Setyanto, AR, dkk. (2015). Kajian Strategis Pemberdayaan UMKM dalam Menghadapi Perdagangan Bebas Kawasan ASEAN. Etikonomi, 14(2), 205-220.

Tahitu, M.E. (2015). Pengembangan Kapasitas Pengelola Sagu dalam Peningkatan Pemanfaatan Sagu di Maluku Tengah Provinsi Maluku. Thesis. Bogor: Sekolah Pascasarjana Institut Pertanian Bogor.

Tahitu, ME, dkk. (2016). Strategi Pengembangan Kapasitas Pengelola Sagu di Maluku Tengah Provinsi Maluku. Sosiohumaniora, 18(1), 39-46.

Timisela, NR, dkk. (2014). Manajemen Rantai Pasok dan Kinerja Agroindustri Pangan Lokal Sagu di Provinsi Maluku : Suatu Pendekatan Model Persamaan Struktural. Agritech, 34;2, 184-193. 